\title{
APLIKASI ABSENSI MAHASISWA BERBASIS RADIO FREQUENCY IDENTIFICATION (RFID) DI INSTITUT SAINS DAN BISNIS ATMA LUHUR PANGKALPINANG
}

\author{
Yurindra' ${ }^{1}, \operatorname{Sarwindah}^{2}, \operatorname{Marini}^{3}$, Anisah $^{4}$ \\ ${ }^{1}$ Teknik informatika ISB Atmaluhur, ${ }^{2}$ Prodi Bisnis digital ISB Atmaluhur, ${ }^{3}$ Sistem Informasi ISB \\ Atmaluhur, ${ }^{4}$ Sistem Informasi ISB Atmaluhur \\ 1yurindramail@gmail.com,${ }^{2}$ indah_syifa@atmaluhur.ac.id, ${ }^{3}$ arinimarini44@atmaluhur.ac.id, \\ anisah@atmaluhur.ac.id
}

\begin{abstract}
ABSTRAK
Banyaknya permasalahan yang timbul umum terjadi di dunia akademis yaitu mengenai presensi kehadiran mahasiswa. Data kehadiran mahasiswa merupakan indikator penting bagi sistem pembelajaran di perguruan tinggi, terlebih pada tingkat kehadiran mahasiswa tertentu pada mata kuliah tertentu dan rekaman data keterlambatan mahasiswa pada mata kuliah tertentu maupun mahasiswa tertentu, sehingga nanti akan dapat dijadikan sebagai bahan evaluasi bagi perguruan tinggi.Umumnya terjadi kesulitan pendataan pada jam masuk dan keluar pada tiap mata kuliah yang sedang berjalan, yang menjadikan laporan absensi mahasiswa hanya merupakan rekaman catatan masuk atau tidaknya mahasiswa bersangkutan, tanpa diketahui waktu keterlambatan mahasiswa tersebut. Aplikasi absensi mahasiswa ISB Atma Luhur Pangkalpinang berbasis Radio Frequency Identification (RFID) yang akan dibangun diharapkan dapat membantu proses pencatatan kehadiran mahasiswa dikelas yang dilengkapi dengan rekaman waktu kedatangan. Model pengembangan yang digunakan dalam penelitian ini adalah model prototipe dengan metode berorientasi objek dibantu dengan beberapa diagram dalam UML. Hasil dari penelitian ini adalah sistem pencatatatan kehadiran mahasiswa terdigitalisasi sehingga dapat mengurangi terjadinya kesalahan dari sisi manusia dalam proses rekapitulasi data serta mampu menyediakan data analisis tentang jumlah dan waktu kehadiran mahasiswa untuk kepentingan pengembangan sistem pembelajaran lebih lanjut.
\end{abstract}

Kata kunci : absensi, rfid, metode_pembelajaran, kartu_absen, absen_digital

\begin{abstract}
Students' attendance is one of the serious problems in academic setting, yet the data of students' attendance plays significantly in terms of teaching and learning system in university. Furthermore, for certain level, the data of students' attendance from several subjects is used for being consideration of university evaluation. However, the mostly appeared problem is the obstacle of gaining the data about when the students start and finish the class for on-going subject since what is recorded only about whether the student was or was not there. It means, there is no measurements of students' lateness. Therefore, the implementation of students' attendance application which is based on Radio Frequency Identification (RFID) for ISB students in Atma Luhur Pangkalpinang is needed to help gaining the data of students' attendance completely (arrival time record is included). This research applied the prototype model as developing model where the object orientation method is helped through UML diagram. The result of the research shows that students' attendance system was digitalized, and it can minimize human error in data recapitulation process and can give data analysis related to frequency and duration of students' attendance to help the needs of teaching and learning development system.
\end{abstract}


Kata kunci : attendance, rfid, learning method, attendance card, digital attendance

\section{PENDAHULUAN}

Presensi kehadiran mahasiswa pada perkuliahan adalah salahsatu faktor penting yang selalu dijadikan indikator dalam menentukan kelulusan mata kuliah maupun menjadi salahsatu indikator dalam membantu memberikan nilai mata kuliah tertentu kepada mahasiswa baik manual maupun terkomputerisasi [1]. Demikian pula kehadiran pendidik dalam hal ini dosen pengampu sangat menentukan arah kebijakan perguruan tinggi pada umumnya. Saat ini absensi perkuliahan di Institut Sains dan Bisnis Atma Luhur Pangkalpinang sudah dilakukan semi terkomputerisasi yaitu dosen akan mencatat kehadiran mahasiswa lalu melakukan input data ke system absensi yang telah disediakan. Perekaman presensi kehadiran mahasiswa pada perkuliahan juga merupakan indikator yang penting dalam mengelola sumberdaya manusia dalam hal ini mahasiswa dan dosen. Informasi yang mendalam dan terperinci mengenai kehadiran dapat menentukan prestasi, produktivitas atau kemajuan perguruan tinggi secara umum. Perangkat yang menggunakan sistem identifikasi dengan frekwensi radio adalah sebuah teknologi yang lama namun terus mengalami pembaruan yaitu sebagai sebuah teknologi yang digunakan untuk membantu manusia dalam melakukan identifikasi dengan tujuan tertentu [2]. Identifikasi dengan frekwensi radio dapat terdiri dari kartu, chip dan peralatan khusus yang mempunyai kode informasi yang sangat unik dengan menggunakan sebuah alat pembacaan yang disebut dengan reader untuk membaca kode yang telah dimiliki kartu atau chip tersebut [3].
Proses presensi yang umum dilakukan oleh mahasiswa selama ini diruangan kelas adalah dengan menandatangani formulir atau dokumen yang dibawa oleh dosen dan berisi nama serta tandatangan mahasiswa yang telah disediakan oleh bagian akademik . Formulir itu merupakan bukti bahwa mahasiswa yang bersangkutan telah mengikuti mata kuliah tersebut. Di ISB Atmaluhur setelah formulir tersebut ditandatangani oleh mahasiswa maka berikutnya adalah dosen pengampu mata kuliah yang bersangkutan harus menginput data tersebut ke sistem yang telah disediakan oleh bagian sistem informasi perguruan tinggi. Kehadiran tersebut akan dihitung oleh sistem dalam tingkatan persentase kehadiran, bila tingkat kehadiran tidak memenuhi $80 \%$ maka mahasiswa tersebut tidak diperkenankan untuk mengikuti ujian tengah semester dan ujian akhir semester. Disamping itu pada hasil rekap kehadiran yang dimasukkan kedalam sistem juga sering terjadi kesalahan input dan ketidaksesuaian dengan data yang sebenarnya, hal ini terjadi dikarenakan kesibukan dosen, biasanya dosen tidak langsung menginputkan data absensi kedalam system sehingga terjadi backlog data yang mengakibat kesalahan input. Disamping itu waktu kehadiran atau keterlambatan mahasiswa tidak tercatat pada sistem ini.

Dalam penelitian ini dapat dilihat beberapa penelitian terdahulu sebagai referensi antara lain yaitu penelitian Eko Budi Setiawan dan Bobi Kurniawan tahun 2015 tentang Perancangan Sistem Absensi Kehadiran Perkuliahan di Universitas Komputer Indonesia (UNIKOM) menggunakan Teknologi Radio Frequency Identification [4]. Lalu selanjutnya 
penelitian oleh Muhammad Ibrohim dan Maya Selvia Lauryn serta Rama Dhanan Jaya pada tahun 2019 mengenai Rancang Bangun Sistem Kehadiran Karyawan berbasis RFID [5]. Penelitian Febrian murti Dewanto, Bambang Agus Herlambang, Aris Tri Jaka Harjanta pada tahun 2017 mengenai Pengembangan Sistem Informasi Absensi Radio Frequency Identification (RFID) Terintegrasi dengan Sistem Informasi Akademik [6]. Penelitian Wagino, M. Edya Rosadi, Arif Wahyudi pada tahun 2017 tentang Aplikasi Perpustakaan menggunakan SmartCard RFID (Radio Frequency Identification) [7]. Penelitian Musfirah Putri Lukman, Husni angrian pada tahun 2018 mengenai Implementasi Teknologi RFID pada Sistem antrian rekam medis pasien di rumah sakit [8].

Dari permasalahan yang terjadi lalu di dukung beberapa penelitian tersebut diatas menunjukan bahwa betapa pentingnya penggunaan teknologi RFID (Radio Frequency Identification) dalam implementasinya pada sistem absensi didalam dunia akademik . Dengan gap penelitian tersebut mendasari untuk mengembangkan aplikasi absensi bagi mahasiswa berbasis RFID di ISB Atmaluhur dengan harapan dapat digunakan untuk menentukan kebijakankebijakan terkait kebutuhan pembelajaran bagi pemangku kepentingan di ISB Atmaluhur.

\section{Tujuan Penelitian}

Tujuan penelitian ini dimaksudkan sebagai bahan referensi bagi pengembangan insitusi pendidikan ISB Atmaluhur pangkalpinang, yaitu dalam hal bahan referensi terkait dengan evaluasi terhadap persentase jumlah kehadiran mahasiswa, persentase jumlah keterlambatan mahasiswa , persentase keterlambatan mahasiswa pada jam kuliah tertentu ( umumnya pagi hari dan sore hari pukul 16.30 pada saat pulang kerja ) kemudian evaluasi terhadap jam masuk dan keluar . Disamping itu pula memiliki tujuan untuk mampu meminimalisir kesalahan input presensi kehadiran manual dan mengimplementasikan absensi secara otomatis sehingga mengurangi beban kerja dosen pengampu mata kuliah .

\section{Manfaat penelitian}

Manfaat penelitian ditujukan bagi institusi ISB Atmaluhur agar dapat mendukung kebijakan yayasan Atmaluhur terkait evaluasi terhadap tingkat kehadiran mahasiswa, tingkat keterlambatan, tingkat keterlambatan pada jam atau waktu tertentu. Disamping itu penelitian ini diharapkan dapat meminimilisir kesalahan input presensi secara manual sehingga mampu mengurangi beban kerja dosen dalam menjalani proses perkuliahan.

\section{METODE PENELITIAN}

\section{Metode dan analisis kebutuhan Pengembangan Perangkat Lunak}

1. Wawancara

Dalam hal ini melakukan wawancara langsung kepada :

a. Ketua Prodi Teknik informatika, prodi Sistem informasi dan prodi bisnis digital di ISB Atma Luhur Pangkalpinang untuk mendapatkan kebutuhan dari masing- masing di tingkat program studi.

b. Dekan fakultas teknologi informasi untuk menyampaikan serta menerima umpan balik tujuan penelitian ini agar dapat dilihat tingkat kelayakan dari penelitian ini. c. Bagian BSI ( sistem ) ISB Atmaluhur untuk memperoleh data tentang 
kesiapan bagian BSI untuk melakukan integrasi ke dalam sistem utama ISB Atmaluhur apabila sistem ini di implementasikan.

2. Tahap awal penelitian ini dilakukan dengan melakukan melakukan evaluasi terhadap data absensi tersebut apakah memenuhi indikator yang diharapkan dalam penelitian.

3. Metode Perancangan

Tahap selanjutnya adalah perancangan sistem dengan metode berbasis object oriented dengan melibatkan seluruh stakeholder yang telah ditentukan sebelumnya.

4. Model pengembangan digunakan pula model Prototype, sehingga dihasilkan sebuah rancangan lengkap dengan aplikasi berupa prototype.

5. Alat yang digunakan dalam tahap pengembangan menggunakan diagram dan aplikasi sebagai berikut :

a. Diagram usecase

b. Diagram aktivitas

c. Diagram sekuen

d. Diagram class

e. Pemrograman PHp

f. Database SQL Server

6. Menganalisa kebutuhan Perangkat keras dan perangkat lunak yang dibutuhkan karena kebutuhan ini akan di komunikasikan kepada yayasan Atmaluhur agar dapat menjadi pertimbangan biaya bila ingin di implementasikan.

\section{Analisis Sistem Berjalan}

Model database absensi yang sedang terjadi di ISB Atmaluhur ditunjukan dalam gambar sebagai berikut yang telah di ekstrak kedalam ekstension excel :

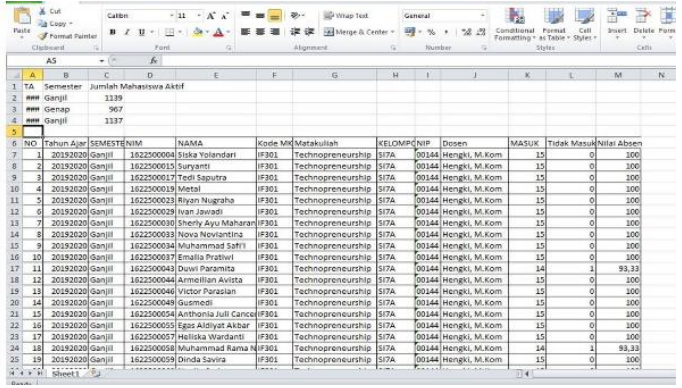

Gambar 1. Model laporan absensi yang sedang berjalan

Penjelasan dari gambar tersebut adalah :

Model absensi yang saat ini digunakan adalah menggunakan aplikasi berbasis web yang tersimpan di server kampus ISB Atmaluhur . Pengisian kehadiran dilakukan oleh dosen pengampu mata kuliah berdasarkan formulir manual di kelas maupun diisi secara langsung ke dalam sistem secara online di kelas. Database yang sudah ada mampu melihat jumlah persentase kehadiran mahasiswa per dosen atau per mata kuliah. Namun permasalahannya adalah bahwa dalam database yang sudah di ekstrak ke excel tersebut diatas tidak mampu untuk melihat detail jam keterlambatan mahasiswa per mata kuliah atau per dosen. Disamping itu data diatas belum mampu menjadi data pendukung untuk melakukan evaluasi terhadap jumlah keterlambatan mahasiswa pada jam dan hari tertentu.

Absensi dosen pengampu

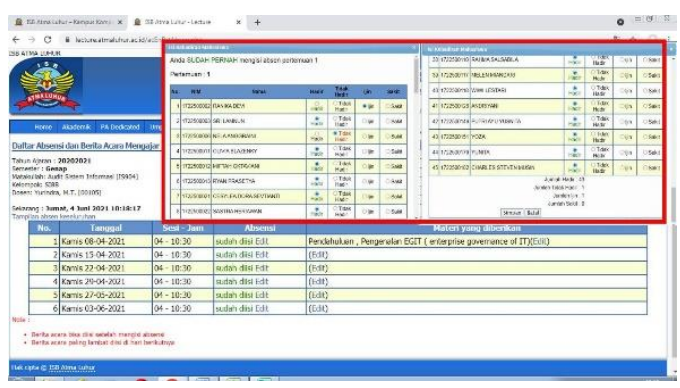

Gambar 2. Absensi per dosen tiap pertemuan 
JURNAL NUANSA INFORMATIKA

Volume 15 Nomor 2, Juli 2021
p-ISSN : 1858-3911, e-ISSN : 2614-5405

https://journal.uniku.ac.id/index.php/ilkom

\section{Perancangan Fisik}

Tahap berikut yang dilakukan adalah perancangan perangkat keras berupa struktur alur perangkat keras yang akan di lakukan pada sistem sehingga di rasa akan mampu memenuhi kebutuhan dan mengatasi permasalahan yang timbul.

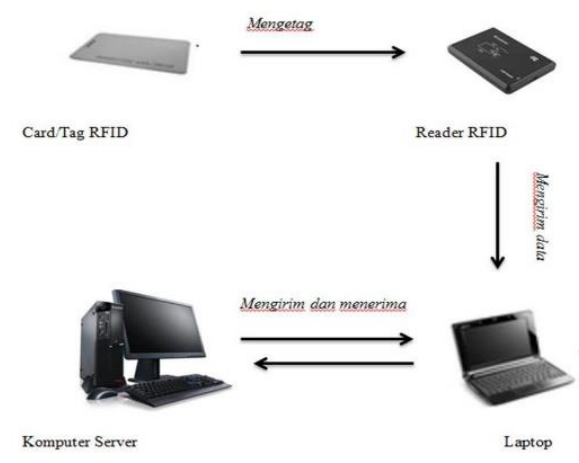

Gambar 3. Rancangan fisik sistem rfid

\section{HASIL DAN PEMBAHASAN}

\section{Diagram hasil rancangan}

1. Berikut ini adalah diagram usecase yang akan digunakan dalam membangun aplikasi :

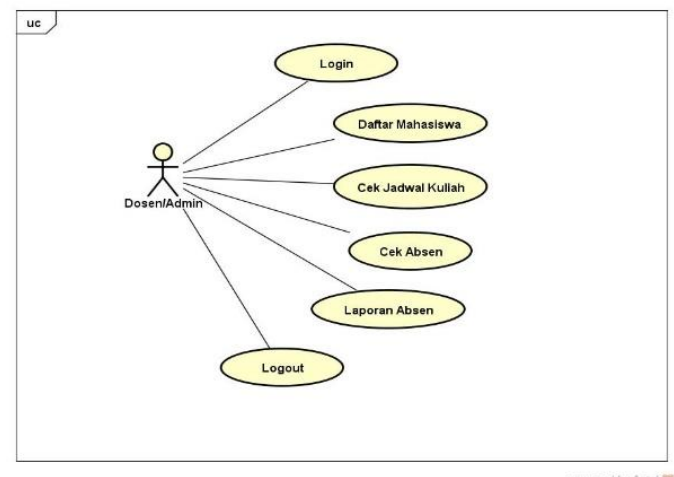

Gambar 4. Diagram usecase absensi Keterangan :

Pada use case diagram admin, ada 4 kegiatan yang bisa dilakukan oleh admin yaitu, admin bisa melakukan login, memeriksa jadwal kuliah, memeriksa absen dan juga bisa logout .
2. Rancangan diagram kegiatan pada saat melaksanakan absensi :

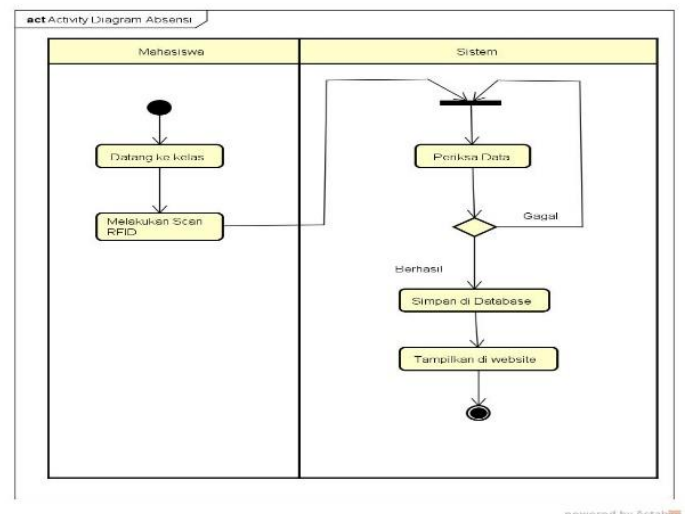

Gambar 5. Diagram activity absensi 3. Rancangan diagram sequence absensi mahasiswa

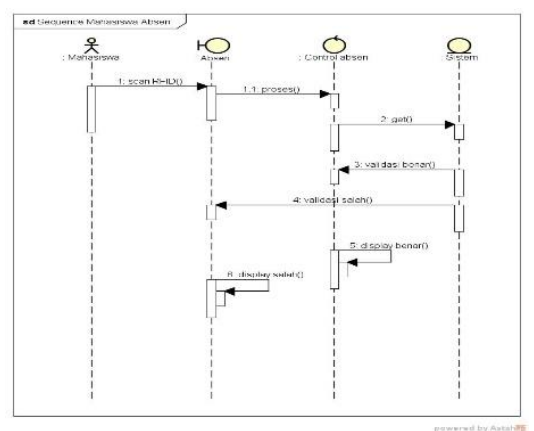

Gambar 6. Diagram sequence absensi mahasiswa

4. Rancangan database

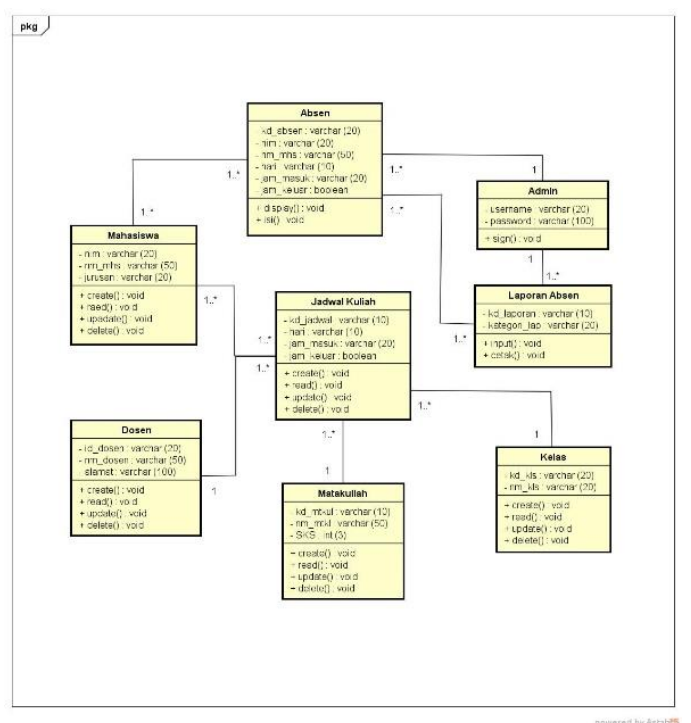


JURNAL NUANSA INFORMATIKA

Volume 15 Nomor 2, Juli 2021

Gambar 7. Rancangan database absensi rfid mahasiswa

\section{Tampilan dan hasil Prototype}

\section{a. Halaman Tap kartu}

Halaman ini digunakan mahasiswa untuk tap kartu RFID dimana mahasiswa memiliki ID yang berbeda-beda.

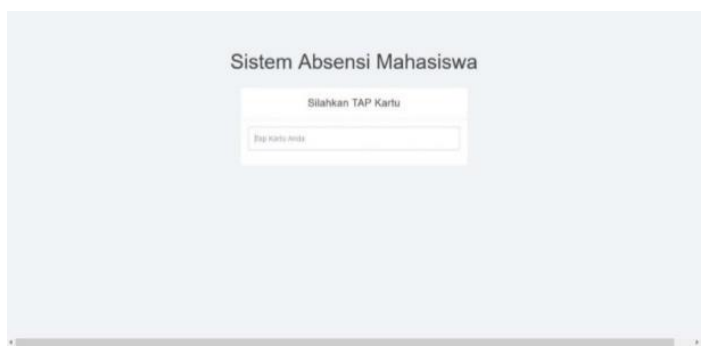

Gambar 8. Halaman Tap Kartu RFID

\section{b. Halaman Login pada admin}

Halaman login akan berfungsi untuk memverifikasi admin yang akan masuk kedalam dashboard.

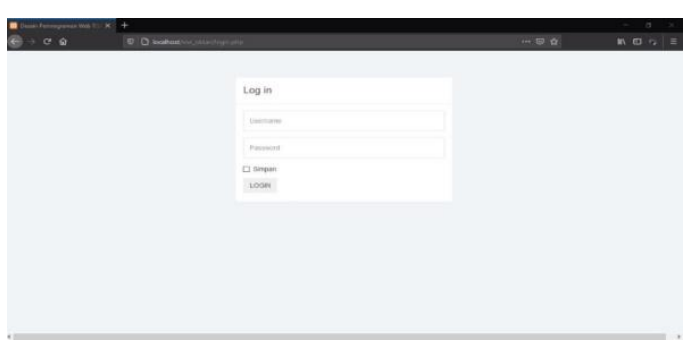

Gambar 9. Halaman Login Admin

\section{c. Halaman Menu Tambah}

Halaman ini digunakan admin untuk input data mahasiswa berupa NIM, Nama mahasiswa, Kode

Kartu RFID, Jurusan.
p-ISSN : 1858-3911, e-ISSN : 2614-5405

https://journal.uniku.ac.id/index.php/ilkom

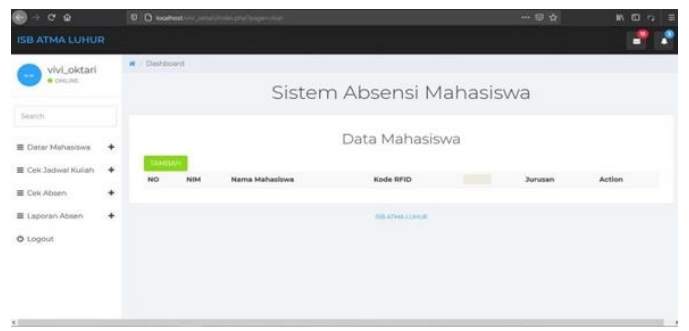

Gambar 10. Halaman Menu Tambah

\section{d. Hasil Prototype}

Berikut hasil dari database yang di ekstrak ke dalam bentuk excel

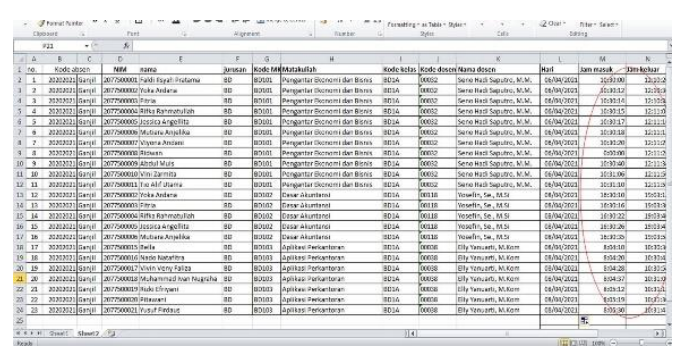

Gambar 10. Hasil aplikasi seluruh dosen dan mata kuliah

Dapat dilihat pada hasil aplikasi tersebut mampu melihat jam masuk dan keluar tiap mahasiswa per dosen/mata kuliah

Hasil aplikasi per dosen

Berikut adalah prototype aplikasi per dosen pengampu tiap pertemuan

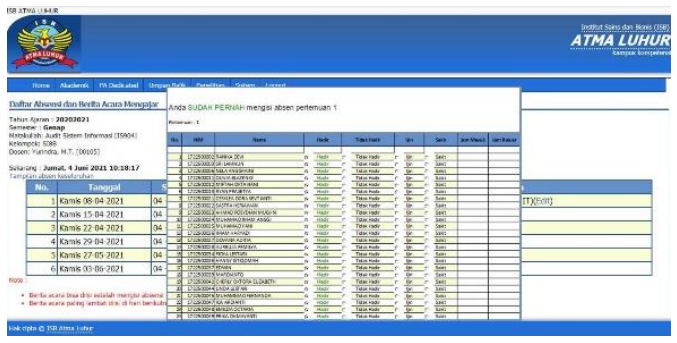

Gambar 11. Hasil aplikasi per dosen 
p-ISSN : 1858-3911, e-ISSN : 2614-5405

https://journal.uniku.ac.id/index.php/ilkom

\section{KESIMPULAN}

Dengan berdasar pada uraian serta bahasan seperti yang telah diterangkan pada bagian sebelumnya, maka dapat disimpulkan bahwa aplikasi yang dibangun mampu untuk menyimpan keluar masuk mahasiswa pada tiap kelas dengan baik, pada bagian aplikasi juga mampu untuk menyimpan data persentase keterlambatan pada waktu tertentu.

\section{SARAN}

Penggunaan RFID masih memiliki kelemahan yaitu masih bisa di gunakan oleh orang lain. Disamping itu sebaiknya dari data yang diperoleh pada implementasi aplikasi ini dapat dibuat lanjutan penelitian untuk melakukan evaluasi terhadap manajemen resiko, pertimbangan untuk membuat penelitian tentang sistem pendukung keputusan bagi data yang telah diperoleh melalui aplikasi ini.

\section{DAFTAR PUSTAKA}

[1] Etin indrayani, "Pengelolaan sistem informasi akademik perguruan tinggi berbasis teknologi informasi dan komunikasi ( TIK )," Jurnal Penelitian Pendidikan Vol. 12 No. 1, April 2011, 2011.

[2] Saputra D,Cahyadi D,Harsa Kridalaksana A,"Sistem Otomasi Perpustakaan Dengan Menggunakan Radio Frequency Identification (RFID), " J.Inform Mulawarman, 2010.
[3] Ganjar turesna,Wahyu P. ,'Proteksi sistem keamanan kendaraan mobil menggunakan rfid berbasis MCU ATMega 328," Jurnal TIARSIE 16.2, 2019.

[4] Coreit j, Setiawan E, Kurniawa B,"Perancangan sistem absensi kehadiran perkuliahan dengan menggunakan radio frekwensi identification ( rfid )," 2015.

[5] Ibrohim M, Lauryn M, Jaya R. ,"Rancang bangun sistem kehadiran karyawan berbasis radio frekwensi identification ( rfid ),"Prosisko, 2019.

[6] Murti DF, Agus HB, Tri JHA,"Pengembangan sistem informasi absensi berbasis radio frekwensi identification ( rfid) terintegrasi dengan sistem informasi akademik," J inform , 2017.

[7] Wagino W, Rosadi ME, Wahyudi A.,"Aplikasi perpustakaan menggunakan smardtcard rfid,’Techno J ILM, 2017.

[8] Lukman MP, Angriani H.,'Implementasi teknologi rfid pada sistem antrian rekam medis pasien dirumah sakit," ILK J ILM, 2018.

[9] Akbar iskandar, Muhajirin , Lisah ,"Sistem keamanan pintu berbasis arduino mega,"JI UPGRIS vol3. 2017.

[10] Yurindra, Dirga.,"Sistem keamanan ruangan dengan perekaman visual berbasis radio frekwensi identification dan PHP di loka monitor spektrum frekwensi radio," Sisfokom, 2013. 